\title{
Static and dynamic camber behavior of uniaxial and biaxial post-tensioned fully, limited, and partially unbonded pre- stressed concrete slab
}

\author{
Rana I.K. Zaki*(D) ${ }^{1}$, Hussam K. Risan ${ }^{1}(\mathbb{D})$ \\ 1 Engineering Department, College of engineering, Al-Nahrain university, Baghdad (Iraq), \\ *Correspondence: rana.i.zaki@nahrainuniv.edu.iq
}

Received: 26.02.2021; Accepted: 03.11.2021; Published: 31.12.2021

Citation: Zaki, R. and Risan, H. (2021). Static and dynamic camber behavior of uniaxial and biaxial post-tensioned fully, limited, and partially unbonded pre-stressed concrete slab. Revista de la Construcción. Journal of Construction, 20(3), 544558. https://doi.org/10.7764/RDLC.20.3.544.

\begin{abstract}
Pre-stressed members in various structures are gaining popularity among engineers in many parts of the world because pre-stressed strands offer better stability, serviceability, economy, aesthetics, and structural efficiency. The profile of the strand greatly influences the tensile strength of concrete. The force exerted by the strand on the concrete counterbalances internal tensile forces. A construction engineer's principal goal is to build an excellent strength structure without sacrificing agility and cost-effectiveness. This study's main objective is to model numerically different pre-stressed concrete slabs to understand and predict the upward deflection (camber) behavior of uniaxial and biaxial pre-stressing of unbonded concrete strands in the static and dynamic behavior and the maximum moments of pre-stressed concrete members by considering previous experimental work as a benchmark for validation. Particular emphasis was placed on the unbonded post-tensioned pre-stressed slab parameters that influence the mid-span upward deflections and internal moments in linear and nonlinear crack analysis. This study also investigated the effect of strand profiles, strand areas, number of strands, strand eccentricities, loading types, and level. It looked into full and partial pre-stressing with uniaxial and biaxial pre-stressing directions. The numerical dynamic characteristics in terms of members' natural frequency with such parameters were found. This study used a finite element numerical model for the analysis of linear and cracked sections and concluded that the upward deflection (camber) of uniaxial and biaxial one-way and two-way partially unbounded prestressed concrete slabs is affected by the strand's profile, area, and number and eccentricity; the loading type and value; and the pre-stressing level in static and dynamic analyses.
\end{abstract}

Keywords: free vibration; biaxial prestressing; post-tensioning; partial prestressing; strand profile.

\section{Introduction}

The most significant development material that plays a magnificent role in the field of construction is concrete. However, at the same time, the weakness due to the tension of concrete still arises. The reinforced concrete system fortified to beat this weakness. Recent improvements in prestressed concrete structures and their utilization have expanded because of the advantage of the compressive stresses actuated by the strands in the prestressed concrete member before loads are applied and before the tensile stresses are generated in the section of the member. Prestressed concrete members have become a common practice in constructing a structure because of its greater stiffness than traditional reinforced concrete sections. This research was initiated to evaluate the influence of strand profile and eccentricity on the flexural behavior of post-tensioned unbonded 
prestressed concrete members. A comprehensive literature review was conducted in two parts. The first part deals with the experimental studies on post-tensioned prestressed concrete members, and the second part deals with some numerical studies that matched with the comparable experimental data.

This study is based on the previous work of (Cooke et al., 1981). Experimental tests are carried out to assess nine unbonded strands' flexural strength in uniaxial pre-stressed concrete and three bonded strands in uniaxial pre-stressed concrete one-way slabs. Because of the importance and clarity of the experimental data given by (Cooke et al., 1981), the present study's authors adopted the data. They used it as a benchmark for the evaluation of numerical results with extended numerical parametric investigation. Note that, due to the absence of previous studies regarding the biaxial prestressed members. Even (Cooke et al., 1981) trial was not conducted for direct comparison of biaxial prestressing unbonded tendons, which this study intends to achieve. Furthermore, most of the pre-stressed concrete slab-column connections trials were conducted with unbonded prestressed concrete slabs (Kang et al., 2015). They tested bonded pre-stressed concrete slab under cyclic loading to assess the connection under seismic loading ((Warnitchai et al., 2004).

The flexural behavior of fully and partially pre-stressed concrete in different categories, such as ultra-high, high, lightweight, and normal weight concrete beams, were examined significantly. In contrast, many factors that may affect flexural ductility have been considered (Padmarajaiah \& Ramaswamy, 2002; Lorenc \& Kubica, 2006; Bondy et al., 2013; Meng et al., 2013). Du and Tao (1985) investigated experimentally and analytically the effects of mutable reinforcement ratio on the stresses in unbonded and bonded strands in partially pre-stressed concrete beams under flexure. Yi and Du Gongchen (1991) investigated the pre-stressed problem experimentally. They demonstrated that the span-to-depth ratio has a reciprocal effect on the ultimate stresses in partially pre-stressed concrete beams with unbonded strands under concentrated mid-span loading conditions.

Naaman and Alkhairi (1991) and Naaman and Alkhairi (1992) reviewed previous experimental results since 1960 and proposed a prediction equation. A safety factor modified the predicted equation to compute the ultimate stresses in a fully and partially pre-stressed unbonded concrete beam. The proposed equation was improved in their subsequent study by considering the loading conditions and the member's span-to-depth ratio. In 2006, Manisekar and Senthil, 2006 predicted an empirical equation to compute the ultimate stresses in a simply-supported pre-stressed concrete beam with unbonded post-tensioned strands. Yang and Kang (2011) presented the prediction of ultimate stresses and the elongation of strands in a simply supported post-tensioned concrete beam by considering the effect of strand profile, span-to-depth ratio, and the loading conditions. Kang et al. (2015) and Hamed and Frostig (2006) presented these predictions numerically using finite element analysis based on previous experimental work and the influence of bonded and unbonded strands for different post-tensioned concrete members on the flexural and shear performance.

Kumar and Venkat (2013) used a genetic algorithm to optimize a simply-supported pre-stressed beam subject to live and dead loads. In that study, the cost ratio was taken as an objective function. They found that the cable profile considerably affects the optimum cost in a beam length of $15 \mathrm{~m}$. The percentage in optimum cost is $4.22 \%$ higher for the parabolic cable profile than the straight-cable profile. Khan et al. (2013) stated that the profile of strands could be represented by B-spline, which is more economical than the parabolic profile provided that stresses in the structural element are kept below the maximum limit states of stresses. Colajanni et al. (2014) presented an optimal steel reinforcement layout procedure in designing the pre-stressed concrete beam.

This study's main objective is to model numerically different pre-stressed concrete slabs to understand and predict the upward deflection (camber) behavior of uniaxial and biaxial pre-stressing of unbonded concrete strands in the static and dynamic behavior. The finite element analysis SAFE software Ver. 16 is adopted. Analysis validity was verified by comparing the results of this study with past experiments reported in the literature. A parametric study conducted to evaluate the effect of various design parameters on post-tensioned concrete slabs' strength and behavior that are fully, limited, and partially prestressed. Particular emphasis was placed on the unbonded post-tensioned pre-stressed slab parameters that influence the midspan upward deflections and internal moments in linear and nonlinear crack analysis. The evaluated parameters comprised various strand profiles, strand areas, number of strands, strand eccentricities, and loading types. The present study considered 
two pre-stressing directions, namely, uniaxial pre-stressing and biaxial pre-stressing, and their influence on the slab's total capacity.

\section{Prestressing classification and ACI code provisions}

The pre-stressing of the concrete can be classified in several ways. The first method is based on the origin of the prestressing force, that is, by what method the pre-stressed force is generated. Pre-stressing force has four types: mechanical, hydraulic, electrical, and chemical. The second method involves the location of the pre-stressed strand within the concrete structure. Pre-stressing location is classified into two types: external and internal. The third and essential classification method is based on the sequence of concrete casting and tension on the strand. Pre-stressing classification sequence has two types: pre-tensioning pre-stressing, which is applied on the strand before concrete casting, and post-tensioning pre-stressing, which is used on the strand after concrete casting. The fourth method is based on the strand shape to be pre-stressed and classifies pre-stressing shape into two types: straight and parabolic. The fifth method is based on the amount of pre-stressing force and classifies pre-stressing amount as types: full, limited, and partial. The sixth and final method is based on the number of directions in which the strand is pre-stressed. The pre-stressing number of directions is classified as uniaxial, biaxial, and multi-axial (McCormac \& Brown, 2015).

The analysis of pre-stressed members can be different for the three different stages of loadings. The initial stage can be subdivided into two sub-stages: loading during steel tension and loading at the transfer of pre-stressed concrete. The intermediate stage includes loads during the transportation of the pre-stressed members. The final stage is also subdivided into loading at service, loading during operation, and ultimate loading during final events (McCormac \& Brown, 2015). (318-19 Building Code Requirements for Structural Concrete and Commentary, 2019) specifies maximum tensile stress under service load in the pre-compressed tensile zone to classify the pre-stressed members into the three different types (based on the amount of pre-stressing), as shown in Section 25.4.2. These classifications are designated as Type I (uncracked-class U), Type II (transitional-class T), and Type III (cracked-class C). The extreme fiber stresses associated with these classes are given in ACI Table 24.5.2.1. These classes' definition eliminates the ambiguity created by the terms full, limited, and partial pre-stressing. In full pre-stressing, the pre-stressing level is adjusted such that approximately no tensile stress is allowed in concrete under service loads (uncracked-class U classification). In limited pre-stressing, the level of pre-stressing is calibrated such that the tensile stress under service loads is approximately within the cracking stress of concrete (transitional-class T). Finally, partial pre-stressing occurs when the pre-stressing level is calibrated. Given service loads, the crack width under tensile stresses is within the allowable limit (cracked-class C). Sections 24.5.3 and 24.4.4 of the ACI code specify the permissible concrete stresses at transferring pre-stressing and service loads. Section 20.3.2.5 illustrates the allowable tensile stresses in pre-stressed reinforcements. Many sections in the ACI code cover concrete workability, concrete mix proportioning, concrete production and control, formwork, transportation, placing, compacting concrete under special conditions, sampling and strength test of concrete, acceptance criteria and inspection, structure testing, grout properties, assembly of pre-stressing and reinforcing steel, and pre-stressing.

\section{Modeling and natural frequency}

In this study, the modeling was conducted using the finite element method by SAFE V16.0 for linear and nonlinear cracked sections. The material and section properties of concrete members, non-pre-stressed reinforcements, and strands are defined. Concrete members and strands are drawn in their correct positions and profile. The dead and live loads with the jacking forces are also assigned to the model. The losses, consisting of short- and long-term losses, are designated as a fixed value. The appropriate boundary conditions are defined and assigned to the model.

The natural frequency of reinforced concrete members is available in many textbooks compared with post-tensioned prestressed concrete members. (TIMOSHENKO et al., 1974) described the pre-stressed beam as a system consisting of two substructures: the cable for tension and concrete for compression. The benefit of determining natural frequency in the diag- 
nosis of structural assessment is dynamic. The natural frequencies are sensitive indicators of structural integrity. The relationship between frequency changes and structural damage is of great importance, especially when a poorly designed pre-stressed member experiences frequency oscillations close to the natural frequency.

\section{Validation}

This study's accuracy of the numerical results was verified by comparing them with the experimental results in static and dynamic responses of pre-stressed concrete members (Cooke et al., 1981) (Collins \& Mitchell, 1991). The first validation problem conducted by (Cooke et al., 1981) was concerned with the deflection at mid-span for simply-supported pre-stressed one-way concrete slabs. This case represents the static trend. The second one was authored by (Collins \& Mitchell, 1991), who studied the natural frequency of simply-supported pre-stressed beams. This case represents dynamic behavior, and this section aims to verify the static and dynamic approaches to numerical modeling used in this research.

\subsection{First validation problem: two pre-stressed concrete one-way slabs}

The pre-stressed one-way slabs, namely, Slabs 4 and 5, tested by (Cooke et al., 1981), were considered in this study as the first numerical examples for validation purposes. Both slabs are simply supported and pre-stressed with unbonded straight strands. The geometry, strands coordinates, and the position of the applied external load of Slabs 4 and 5 are shown in Figure.1. The ultimate compressive strength of the concrete is $35 \mathrm{MPa}$. The modulus of the elasticity of the pre-stressed strand is 202.1 $\mathrm{GPa}$. The pre-stressing of strands is assumed unbonded, and the pre-stressed loss taken into account is $65 \%$. Table (1) illustrates the differences in the geometries of Slabs 4 and 5. Only linear numerical analysis is used for this comparison to check the linear behavior of the finite element modeling. The deformation in Slabs 4 and 5 is shown in Figure 2 at a load of $20 \mathrm{kN}$. Figure 3 shows the load-deflection curves at mid-span for the experimental and the numerical values. Figure 2 demonstrates a near-congruence between laboratory and numerical results in the linear region. Therefore, the numerical model assumed in this study has succeeded in this region as far as the static loads are concerned.

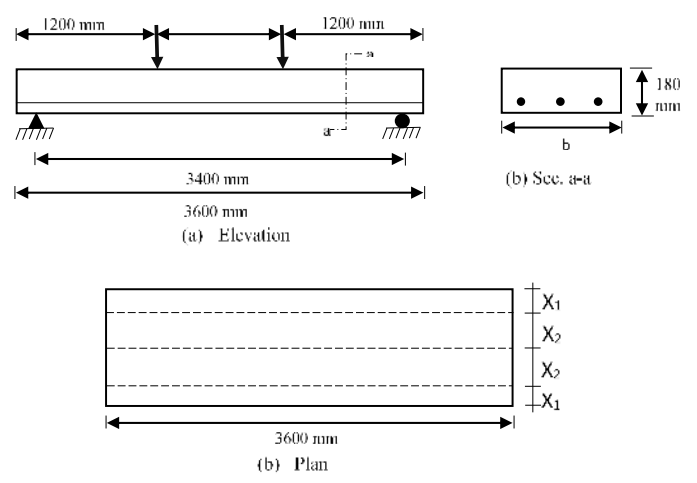

Figure 1. Geometry and arrangement of applied loads of slab 4 and 5 with strands positions.

Table 1. Slabs properties.

\begin{tabular}{cccc}
\hline Member description & Width b $(\mathrm{mm})$ & $\mathrm{X} 1(\mathrm{~mm})$ & $\mathrm{X} 2(\mathrm{~mm})$ \\
\hline Slab 4 & 353 & 55.5 & 121 \\
\hline Slab 5 & 705 & 117.5 & 235 \\
\hline
\end{tabular}




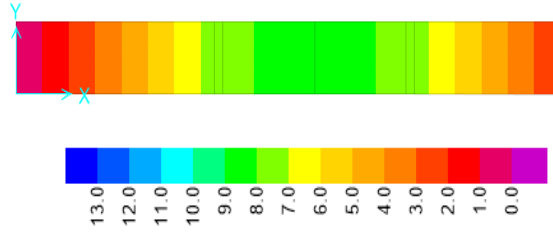

(a)

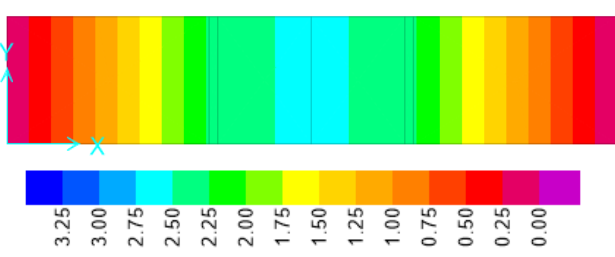

(b)

Figure 2. Deflection shape at load level of $20 \mathrm{kN}$ (a) slab 4; (b) slab 5.

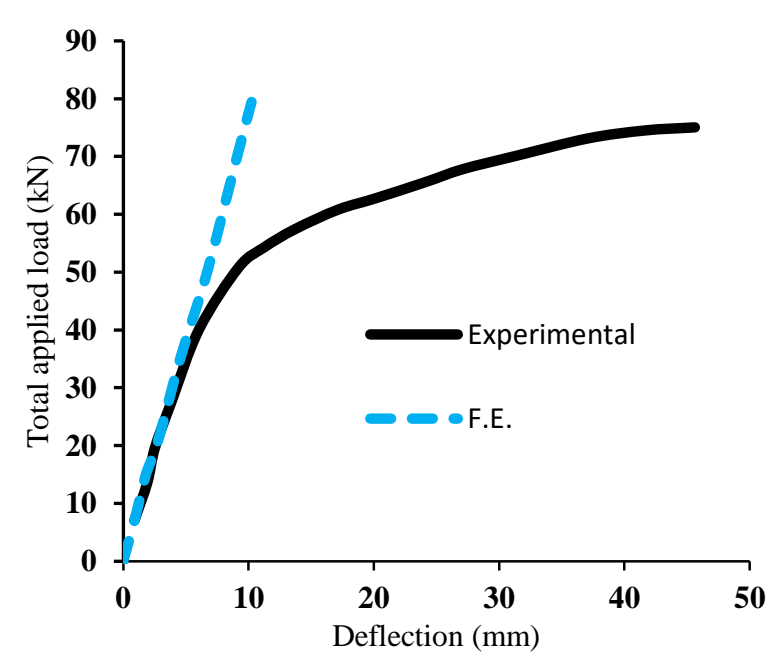

(a)

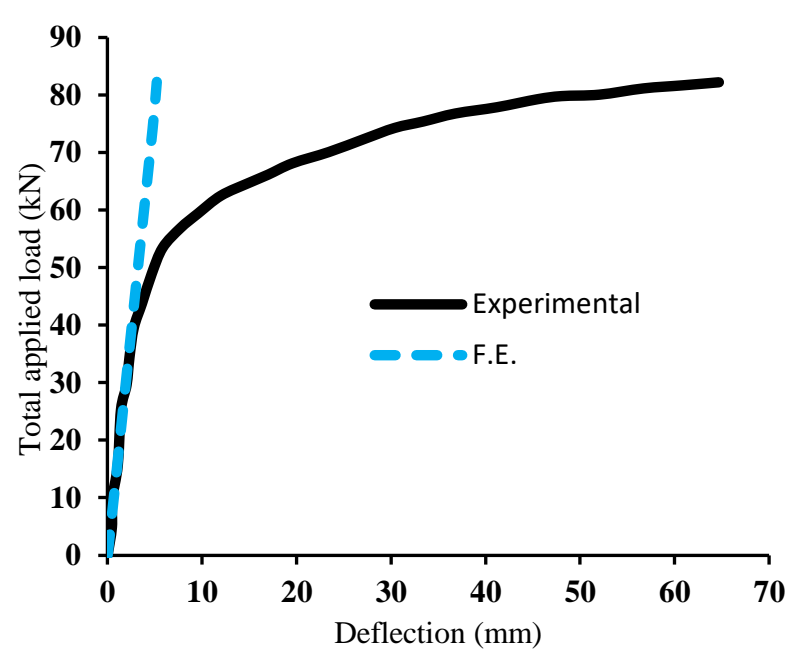

(b)

Figure 3. The load-deflection curve (a) slab 4; (b) slab 5.

\subsection{Second validation problem: a simply-supported pre-stressed beam}

The pre-stressed beams studied experimentally by (Collins \& Mitchell, 1991) were investigated in this study as the second numerical example to confirm the dynamic behavior's finite element modeling. Two types of beams were examined. The first is the simply supported bridge beam pre-stressed with unbonded straight strands. The second is the simply supported roof beam pre-stressed with bonded parabolic strands. The geometries of tested beams are shown in Table (2). The modulus of elasticity of the pre-stressed strand is $195 \mathrm{GPa}$. The natural frequencies for the first three modes $\left(\omega_{1}, \omega_{2}, \omega_{3}\right)$ are calculated numerically throughout the adopted finite element model and compared with the experimental results shown in Table (3). Figure 4 shows the shapes of the first three modes of both beams. Table (3) shows accepted convergence between the experimental and numerical results of the natural frequency and the first three modes' contours. Therefore, this example is considered a validation method for this study's numerical model's behavior in the dynamic stage.

Table 2. Beams properties.

\begin{tabular}{ccccc}
\hline Member description & $\begin{array}{c}\text { Span length } \\
(\mathrm{m})\end{array}$ & $\begin{array}{c}\text { Cross-sectional } \\
\text { area }(\mathrm{mm} 2)\end{array}$ & $\begin{array}{c}\text { Moment of Iner- } \\
\text { tia }(\mathrm{mm} 4)\end{array}$ & $\begin{array}{c}\text { Modulus of elasticity } \\
\text { of concrete }(\mathrm{GPa})\end{array}$ \\
\hline Simply supported bridge beam & 25.0 & 848121 & $2646 \mathrm{e} 11$ & 35 \\
\hline Simply supported prestressed roof beam & 24.4 & 367441 & $2.868 \mathrm{e} 10$ & 27.8 \\
\hline
\end{tabular}


Table 3. Natural frequency in $\mathrm{rad} / \mathrm{sec}$.

\begin{tabular}{ccccccr}
\hline \multirow{2}{*}{ Member description } & \multicolumn{2}{c}{$\begin{array}{c}\text { Experimental by (Collins \& } \\
\text { Mitchell, 1991) }\end{array}$} & \multicolumn{3}{c}{ Present numerical results } \\
\cline { 2 - 7 } & $\omega 1$ & $\omega 2$ & $\omega 3$ & $\omega 1$ & $\omega 2$ & $\omega 3$ \\
\hline Simply supported bridge beam & 35.322 & 141.290 & 317.903 & 33.664 & 134.650 & 302.970 \\
\hline Simply supported prestressed roof beam & 16.638 & 65.334 & 146.843 & 15.754 & 63.014 & 141.780 \\
\hline
\end{tabular}

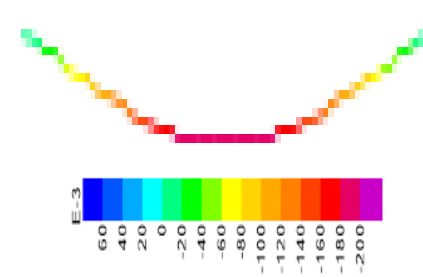

$1 \omega$

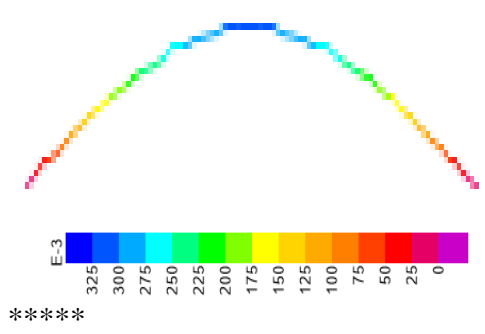

$1 \omega$

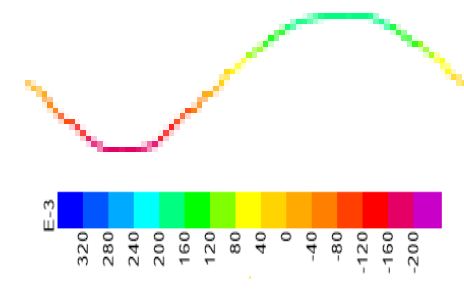

$2 \omega$

(a) Simply supported bridge beam

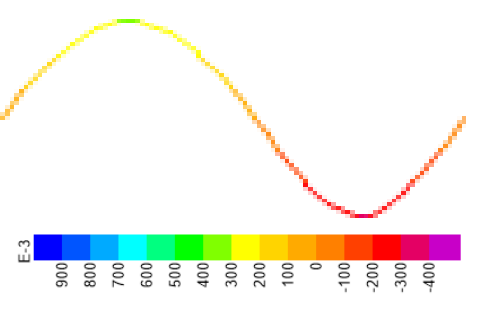

$2 \omega$

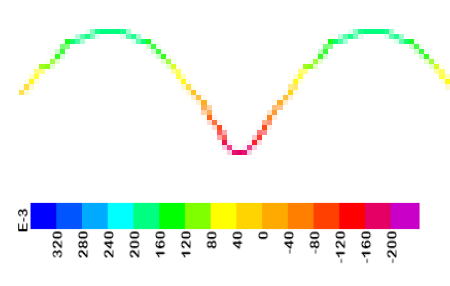

$3 \omega$

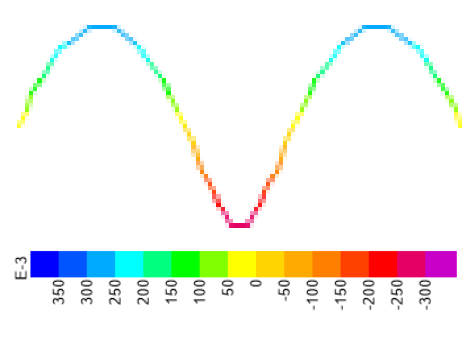

$3 \omega$

(b) Simply supported prestressed roof beam

Figure 4. Mode shapes (a) simply supported bridge beam; (b) simply supported pretressed roof beam.

\section{Parametric evaluation}

Some specific sensitive parameters influencing pre-stressed members' maximum deflection behavior were also investigated, such as strand profiles, strand areas, number of strands, strand eccentricities, and loading types. These parameters were tested numerically for a pre-stressed concrete one-way slab as a uniaxial pre-stressing trend. A biaxial pre-stressing concept was tested using two-way pre-stressed concrete slabs to show their behavior while changing parameters.

\subsection{Uniaxial pre-stressing: simply-supported one-way slab}

Simply-supported one-way slab dimensions, span length, and reinforcement details, as shown previously in Figure.1, are used to conduct a parametric investigation. The parameters that influence the maximum deflection considered in this analysis are strand profiles, strand areas, strand eccentricities, and loading types. Five numerical slab configurations based on the main experimental slab tested by (Cooke et al., 1981), as shown in Table (4), were used in this study to cover a complete parametric evaluating target. These five numerical slab configurations, coded according to Table (4), include three slabs with straight strand profiles and two with parabolic strand profiles. As listed in Table 2, two types of strand areas, 279 and $300 \mathrm{~mm}$, were used with a fixed number of three strands with different eccentricities. 
Table 4. One-way slabs configurations.

\begin{tabular}{ccccc}
\hline Slab name & $\begin{array}{c}\text { Strand } \\
\text { profile }\end{array}$ & $\begin{array}{c}\text { Area of the } \\
\text { strand (mm2) }\end{array}$ & $\begin{array}{c}\text { No. of } \\
\text { strands }\end{array}$ & $\begin{array}{c}\text { Eccentricity } \\
\text { at mid- } \\
\text { span(mm) }\end{array}$ \\
\hline SC4"control" & Straight & 279 & 3 & 60 \\
\hline SC4L & Straight & 279 & 3 & 50 \\
\hline SC4A & Straight & 300 & 3 & 60 \\
\hline SC4P & Parabolic & 279 & 3 & 40 \\
\hline SC4Pe & Parabolic & 279 & 3 & 30 \\
\hline
\end{tabular}

\subsubsection{Strand's profile}

The way the strands were arranged significantly reduces concrete tension. Given its specific curvature, the strand exerts a force on the concrete that counterbalances its tensile forces. In concrete members, transverse loads give rise to sagging bending moments. These moments were counteracted. The strands in most of the pre-stressed members are arranged with their eccentricities toward the member's soffit. The results show an upward deflection of the pre-stressed member on the pre-stressing application. These sagging bending moments are determined by multiplying the pre-stressing force with the eccentricity of the strand. Therefore, the profile of the strand represents the shape of the diagram of the bending moment. Figure 5 shows the load-deflection response for straight and parabolic strands. The parabolic strands profile has zero eccentricity at the support and maximum eccentricities of 40 and $30 \mathrm{~mm}$ in mid-span for slabs SC4P and SC4Pe. At the same time, the straight strands have a $60 \mathrm{~mm}$ eccentricity for the control slab SC4. From Figure 5, changing the strand's profile from straight to parabolic increases the slab's camber. As the center's eccentricity decreases in the curved profile, the mid-span upward deflection increases. An identical sequence is shown for different values of applied external load. The upward deflection (camber) represented a negative sign, whereas downward deflection (sagging) was positive.

\subsubsection{Strand's area}

Increasing the strands cross-sectional area is considered as a parameter effective in improving the behavior of the slab in terms of upward deflection. In a straight strand profile, increasing the prestress area resulted in increasing the efficiency of the beam to resist applied load and produce more upward direction for the same level of applied external load and equivalent prestressing force with identical eccentricity as shown in Figure 6.

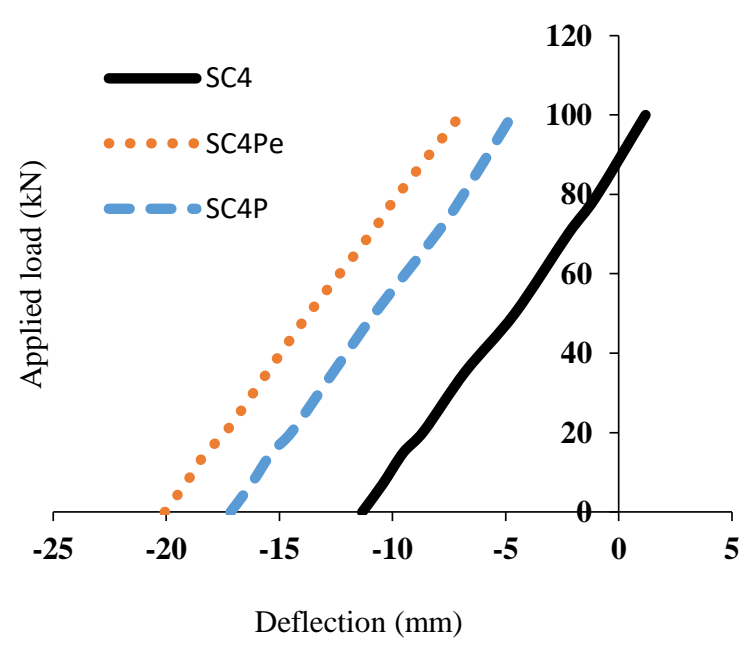

Figure.5. Strand profile

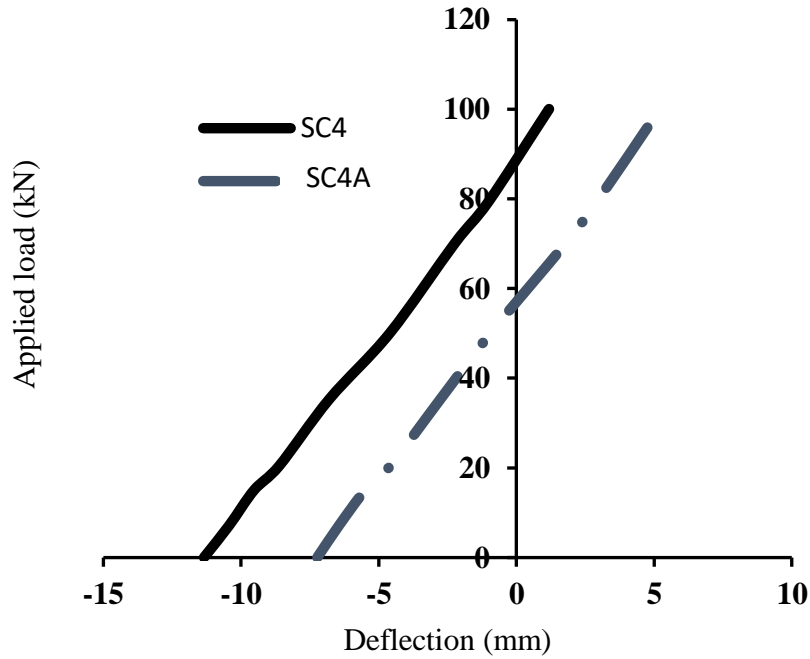

Figure.6. Strand area 


\subsubsection{Strand's eccentricity}

In general, the greater the strand's eccentricity in the pre-stressed concrete members, the greater the capacity to the exposed loads applied load. The effect of two values of eccentricities, namely, $60 \mathrm{~mm}$ and $50 \mathrm{~mm}$ for SC4 and SC4L, is shown in Figure 7. This figure proves that both the upward deflection (camber) is significantly affected by the value of eccentricity value. By increasing the eccentricity lead to an increase in the internal moment capacity of the section. The strand profile in these slabs is straight with identical strand area and prestressing; other slab configurations are illustrated in Table (4).

\subsubsection{Loading type}

The influence of externally applied load configurations on the load-deflection response evaluated using three types of loadings: single concentrated load, uniform load, and line loads with equivalent resultants. The analysis results of the three types of loading are shown in Figure 8 for the straight strand profile of the control slab (Slab SC4). This figure shows that the concentrated load type effect is identical to the line-load class in terms of camber with the equivalent resultant. The uniformly distributed loads show different upward deflection responses, and the net-force value is preserved.

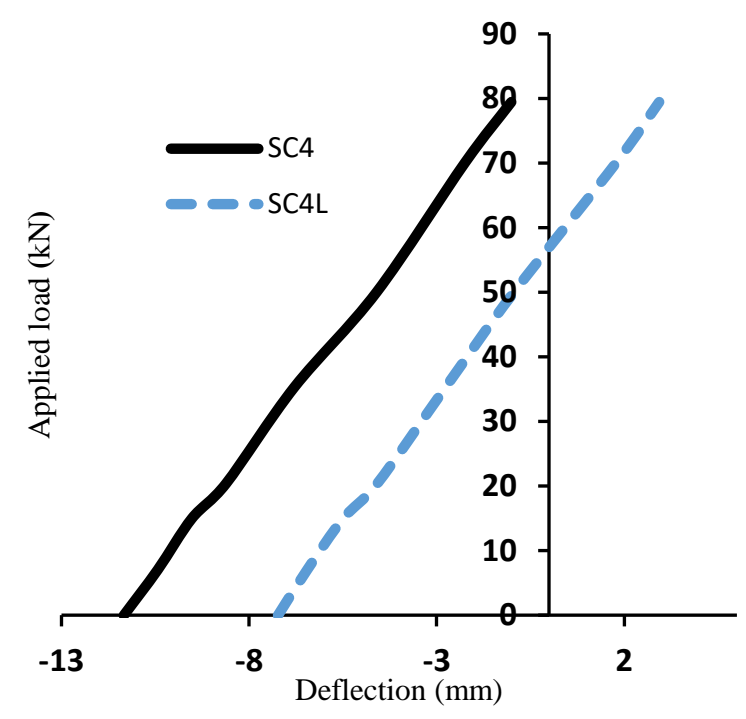

Figure.7. Strand's eccentricity

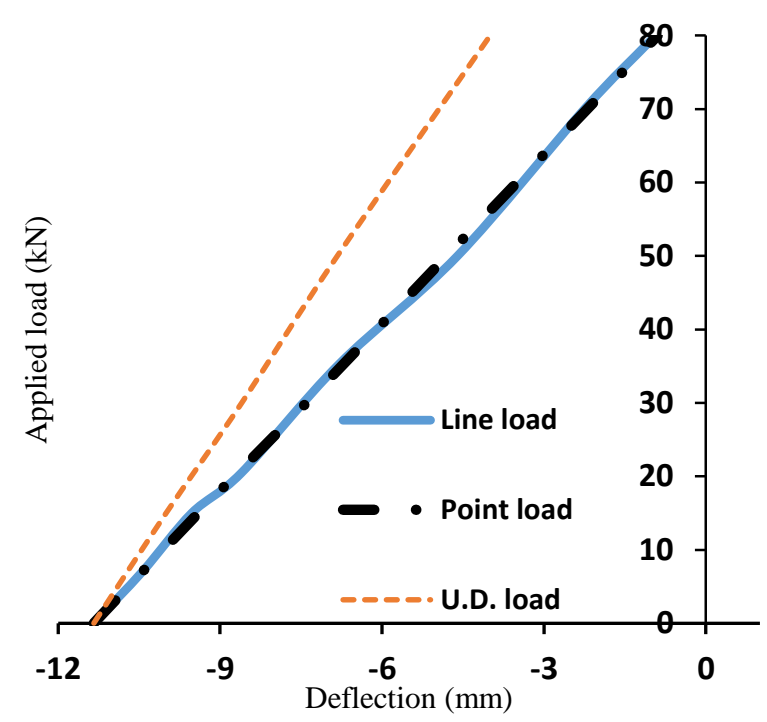

Figure.8. Loading type

\subsection{Biaxial prestressing: simply supported two-way slab}

This section analyzed two pre-stressed two-way concrete slabs numerically. The two slabs are simply--supported and prestressed with unbonded straight strands in the two directions. The slabs' geometry and the distribution of strands are identical for both slabs, as shown in Figure 9. The only difference between the two slabs is a $500 \mathrm{~mm} \times 250 \mathrm{~mm}$ dimensional column in the middle of the second slab. Considering the ultimate compressive strength of the concrete is $41 \mathrm{MPa}$. The pre-stressed strands are assumed unbonded, and the pre-stress loss taken into account is $75 \%$. Based on the two aforementioned basic slabs, 14 slab configurations were used numerically to complete the parametric study intended in this section. Every seven numerical slabs belong to each main slab. These slabs are coded, as shown in Table (5). The table illustrates the strand profile, number of strands, and strand area with eccentricity for each slab. 


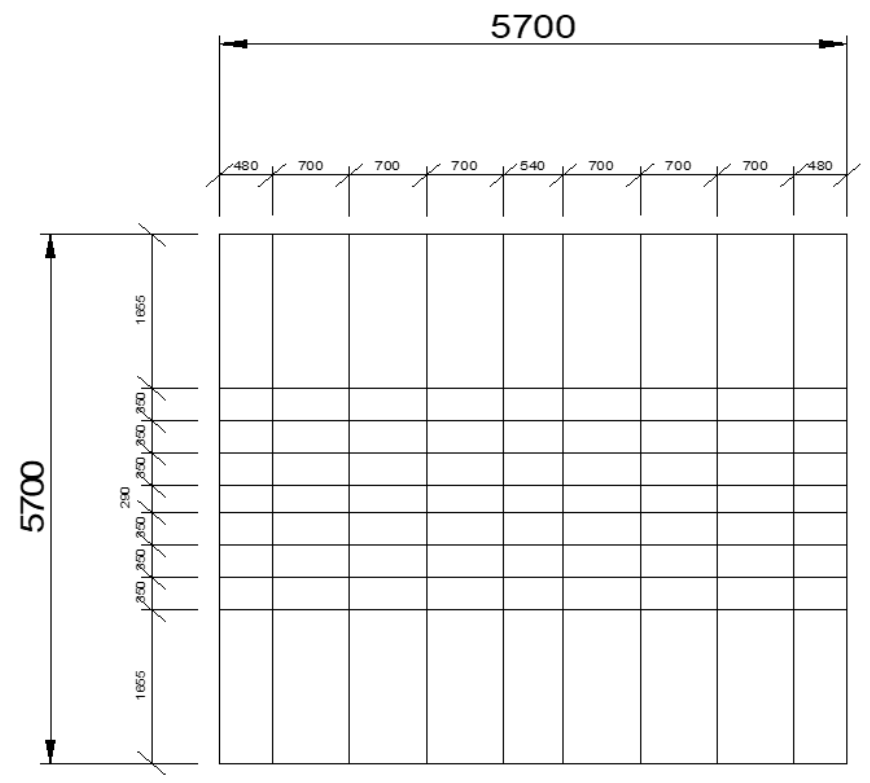

Figure 9. Two-way slab geometry and strand positions.

Table 5. Two-way slab configurations.

\begin{tabular}{|c|c|c|c|c|c|}
\hline Slab description & Slab name & Strand profile & $\begin{array}{l}\text { Strand area } \\
\quad(\mathrm{mm} 2)\end{array}$ & No. of strands & Eccentricity (mm) \\
\hline \multirow{7}{*}{ Two-way slab without column } & twoway "control" & straight & 92.9 & 8 & 60 \\
\hline & tww11 & straight & 92.9 & 8 & 50 \\
\hline & tww22 & straight & 120 & 8 & 60 \\
\hline & tw33 & parabolic & 120 & 8 & 25 \\
\hline & $\operatorname{tw} 23$ & parabolic & 120 & 8 & 25 \\
\hline & twwmp & straight & 92.9 & 10 & 60 \\
\hline & Twwlp & straight & 92.9 & 6 & 60 \\
\hline \multirow{7}{*}{ Two-way slab with column } & twowayc "control" & straight & 92.9 & 8 & 60 \\
\hline & tww11c & straight & 92.9 & 8 & 50 \\
\hline & tww22c & straight & 120 & 8 & 60 \\
\hline & tw33c & parabolic & 120 & 8 & 25 \\
\hline & tw23c & parabolic & 120 & 8 & 25 \\
\hline & Twwmpc & straight & 92.9 & 10 & 60 \\
\hline & Twwlpc & straight & 92.9 & 6 & 60 \\
\hline
\end{tabular}

Figures (10) and (11) show the results of load-upward deflection nonlinear response as a function of applied load for simply-supported two-way slabs with and without the column at the center. Different strand depths and areas were compared regarding the strand profile effect, as shown in Table (5). These figures reveal that changing the strand profile from straight to parabolic improved the slab behavior by increasing the pre-stressed slab's camber and decreasing the slab's downward deflection compared with the control slab. This reduction is caused by the increase in the internal moment, as shown in Figures 12 and 13, for linear and nonlinear analysis. These figures found that the maximum camber is a function of the strand area and eccentricity. The deflected shape at load level $20 \mathrm{kN}$ at ultimate and cracked nonlinear stages are shown in Figures 14 and 15, respectively. Table (6) introduces numerical modal analysis results for the two-way pre stressed slabs with and without 
columns for the first three modes. Fundamental frequency increases when a column is placed in the center of the two-way slab. The first three modes and shapes of the two slabs are shown in Figure 16. Figure (17) shows the effect of inserting the column at the middle of the two-way slab to reduce the maximum upward deflection due to the incresing the stiffness of the slab by reducing the effective span length.

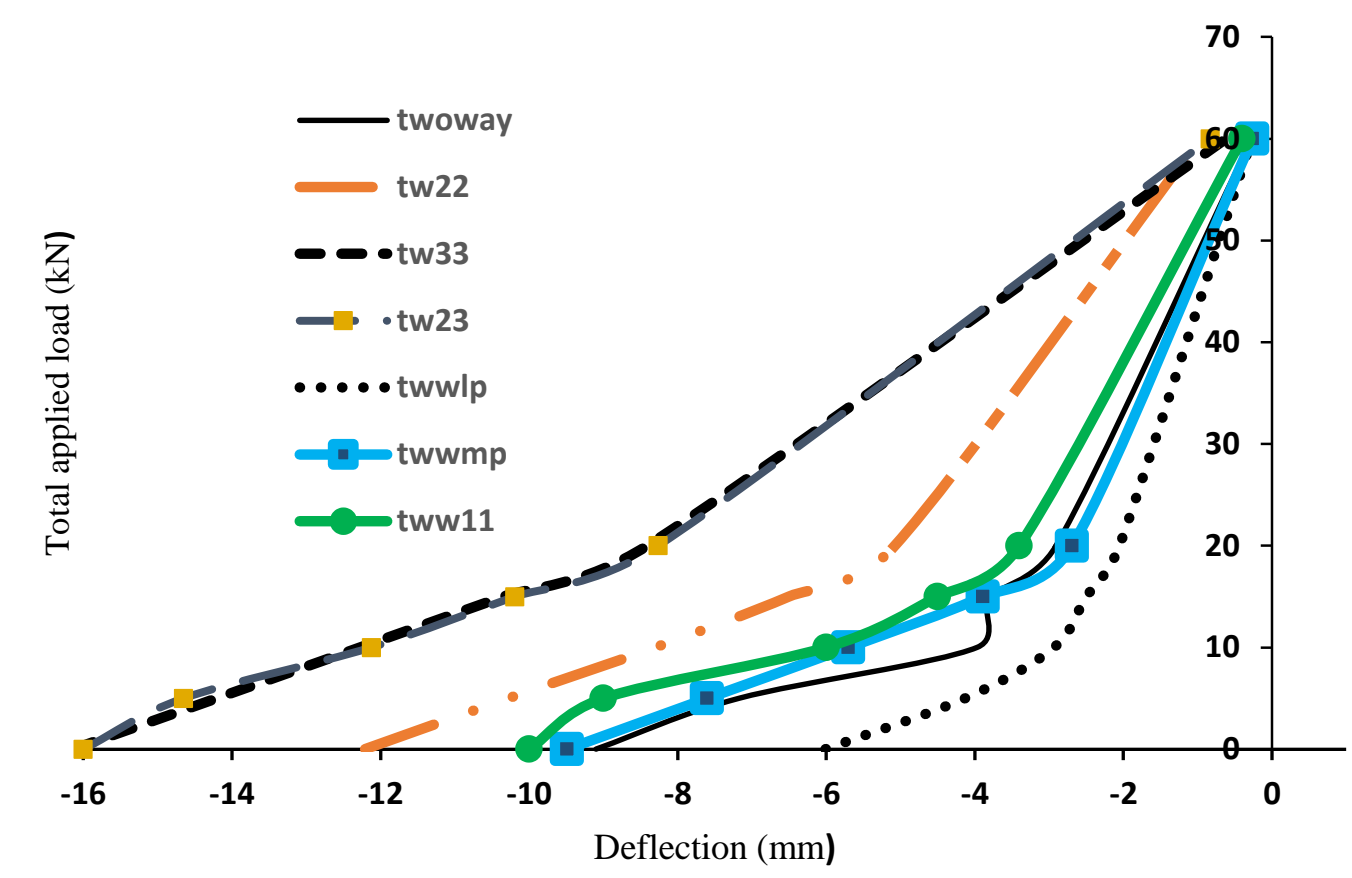

Figure 10. Load-deflection curve for two-way slab without column.

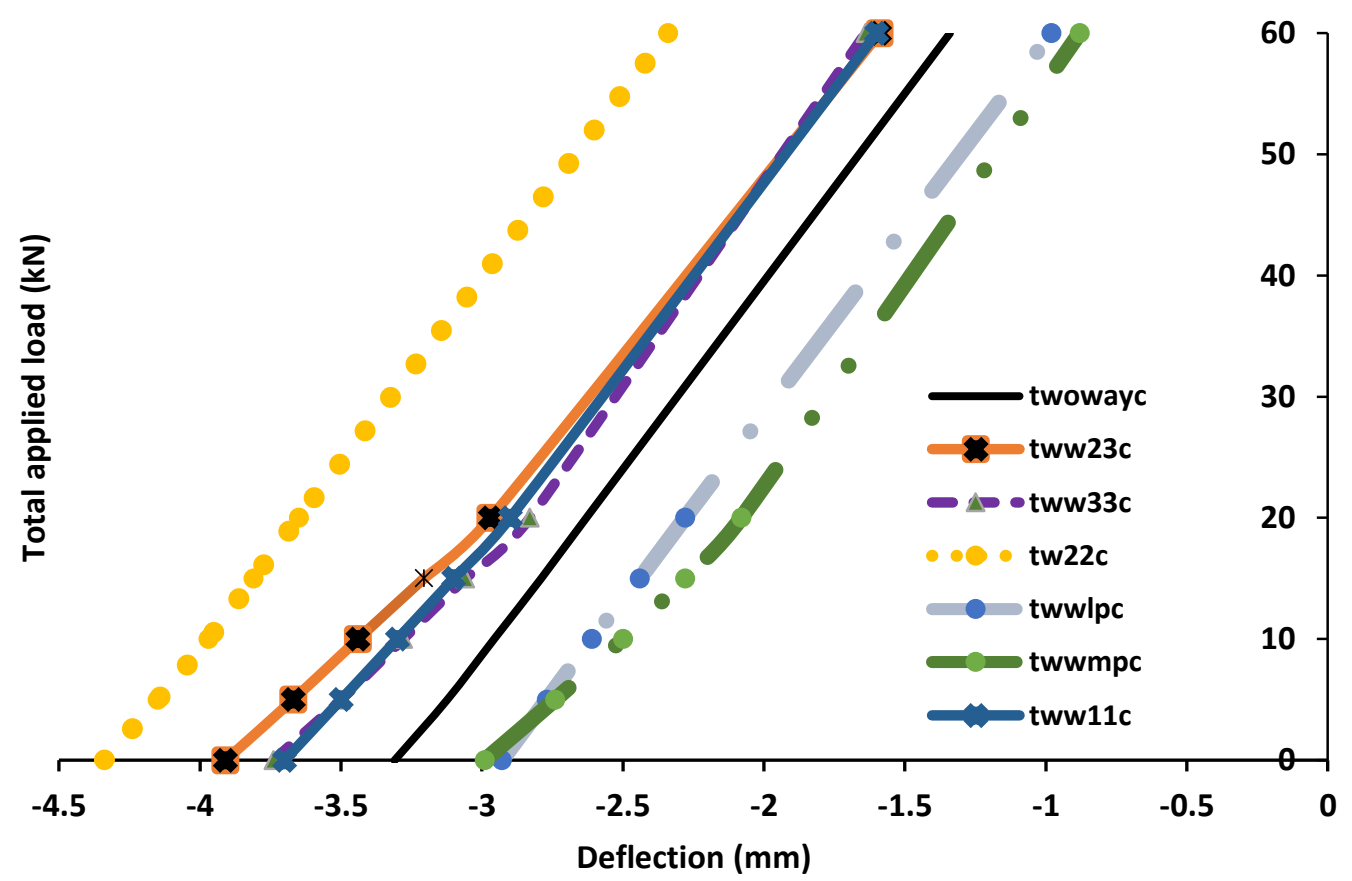

Figure 11. Load-deflection for a two-way slab with column. 


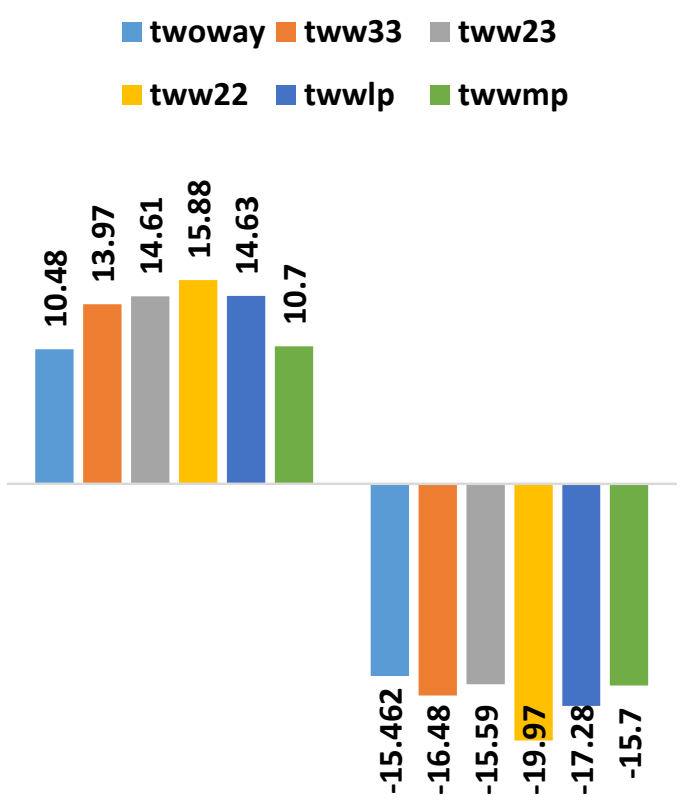

(a)

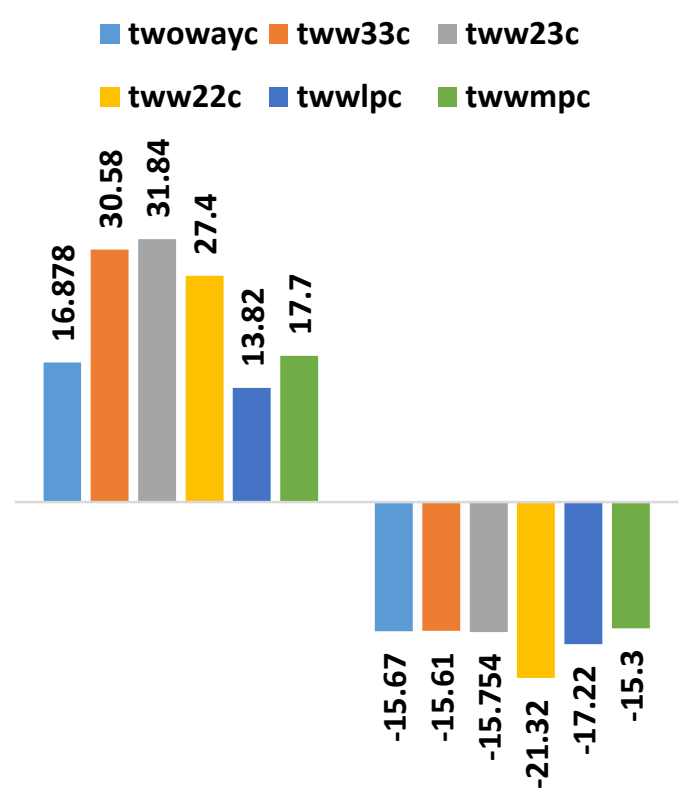

(b)

Figure 12. Maximum linear moments at $20 \mathrm{kN}$ uniformly distributed load (a) two-way slab without column; (b) two-way slab with column.

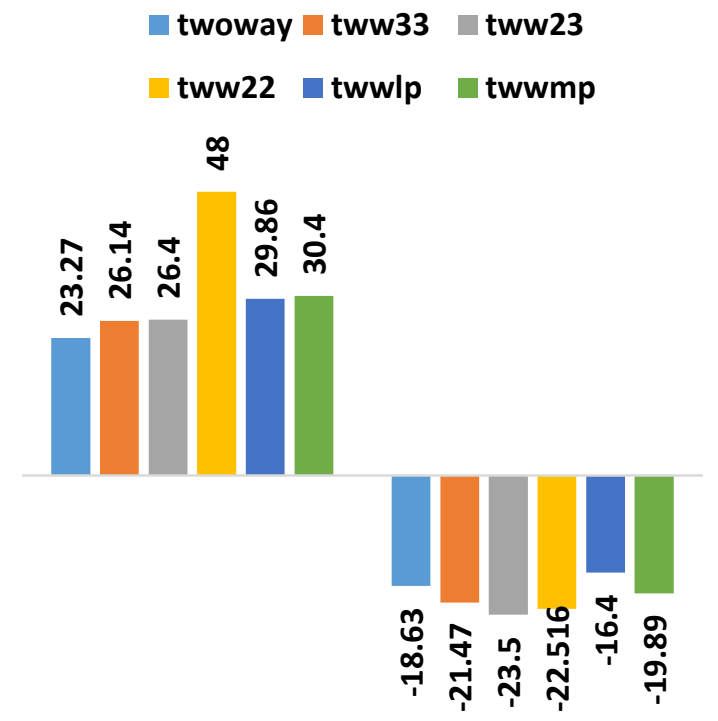

(a)

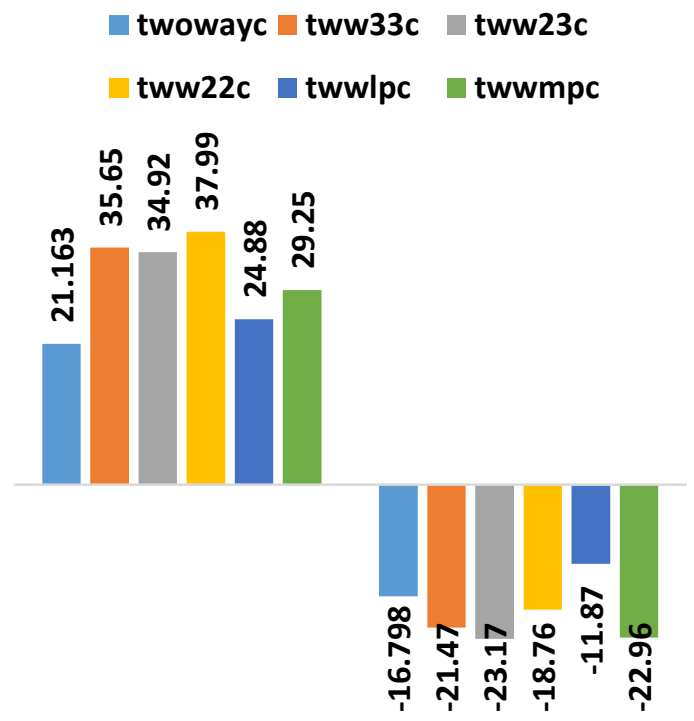

(b)

Figure. 13. Maximum nonlinear moments at $20 \mathrm{kN}$ uniformly distributed load (a) two-way slab without column; (b) two-way slab with column. 


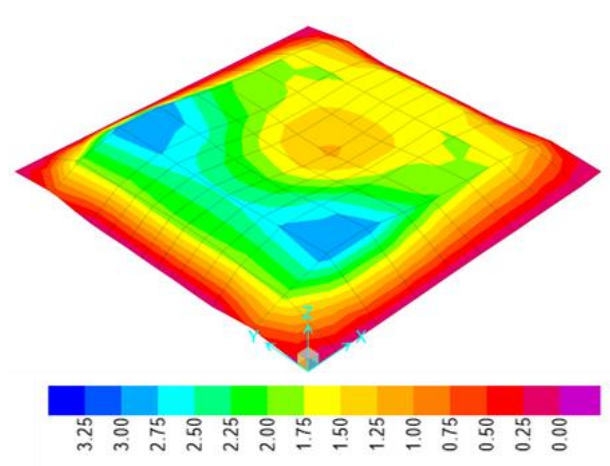

(a)

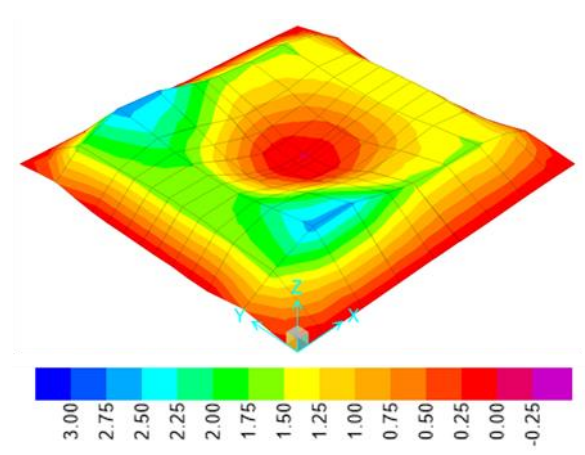

(b)

Figure 14. Deflection shape at load level $20 \mathrm{kN}$ (ultimate) (a) slab without column; (b) slab with column.

Table 6. Natural frequency for the two-way slabs.

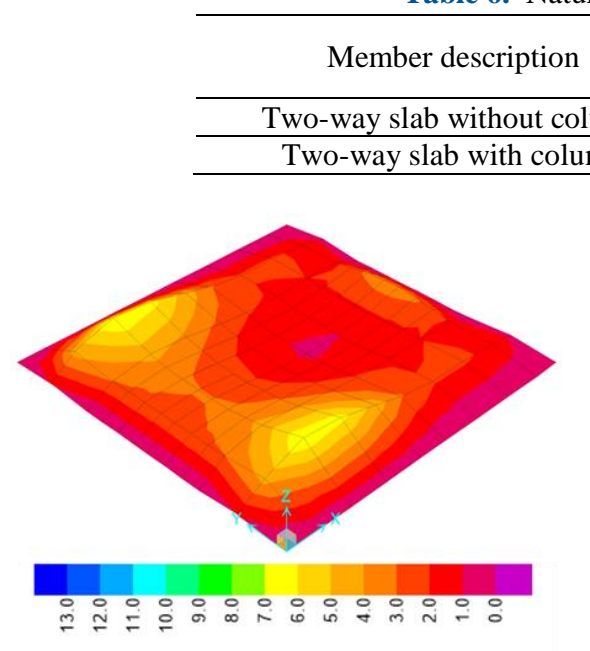

(a)

Figure 15. Deflection shape at load level $20 \mathrm{kN}$ (cracked nonlinear) (a) slab without column; (b) slab with column. 


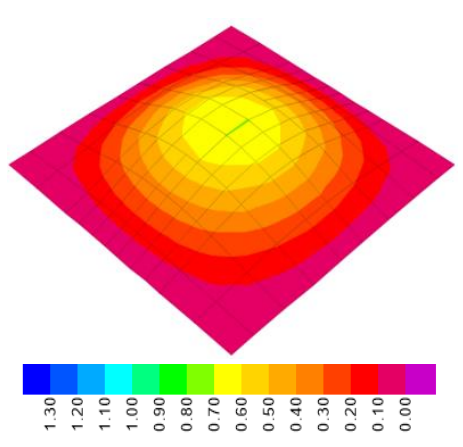

$\omega 1$

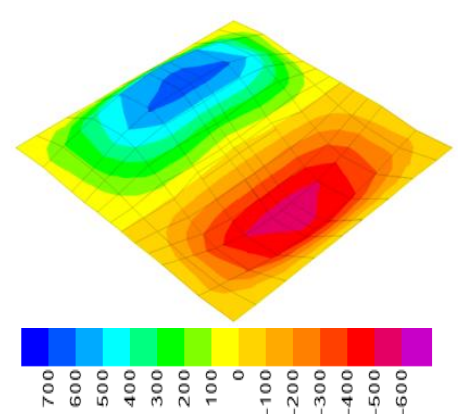

$\omega 1$

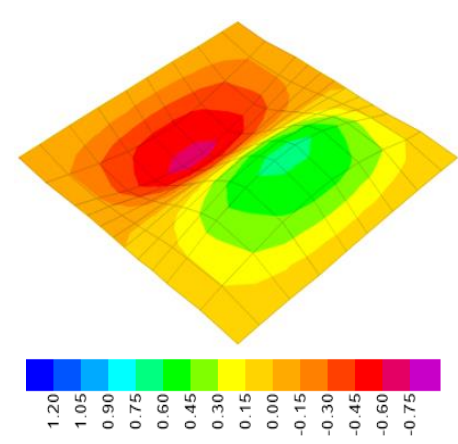

$\omega 2$

(a)

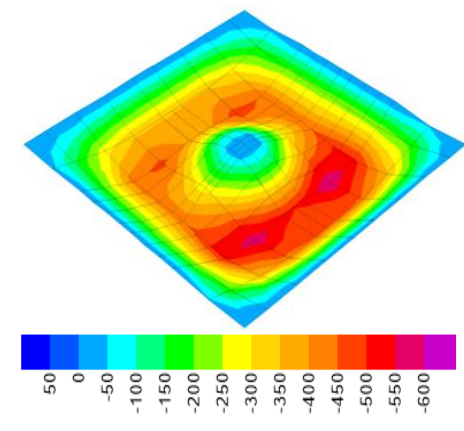

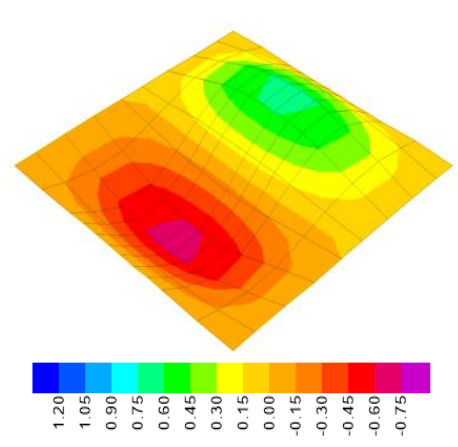

$\omega 3$

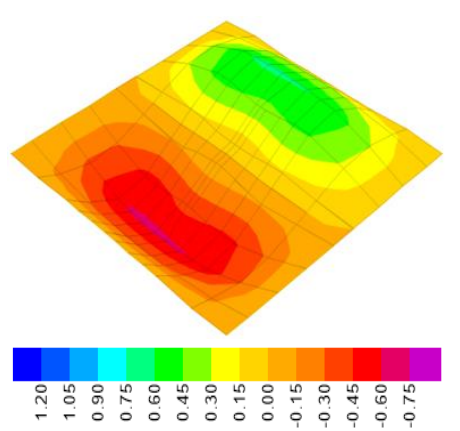

$\omega 3$

(b)

Figure 16. Mode shapes of the two-way slabs (a) two-way slab without column; (b) two-way slab with column.

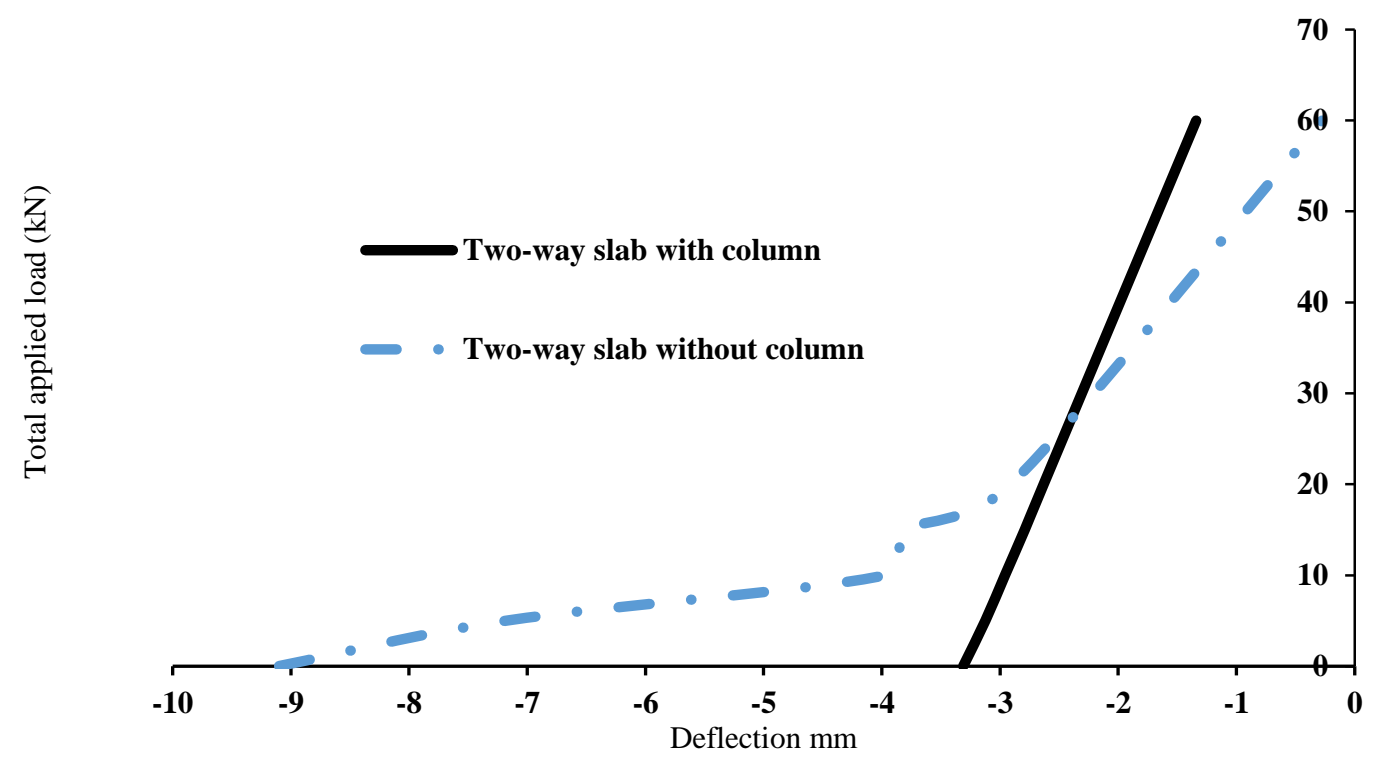

Figure 17. Maximum deflection for the two-way slabs with and without column. 


\section{Conclusions}

This study investigated various strand profiles, strand areas, number of strands, strand eccentricities, loading types and values, pre-stressing levels, and analysis types regarding their effect on the camber of uniaxial and biaxial post-tensioned partially unbonded pre-stressed concrete slab. The camber deflection increases as the strand's profile switches from straight to parabolic in the uniaxial and biaxial pre-stressing of one-way and two-way slabs. This sequence is kept constant for the uniaxial pre-stressing of the one-way slab as applied external force increases. This sequence in the biaxial pre-stressing of the two-way slab disappears gradually as the level of applied external force increases. This study also concluded that the maximum upward deflection fluctuates with the strand's area, eccentricity, and loading type in the uniaxial and biaxial pre-stressing of the concrete slabs. The natural frequency of biaxial pre-stressing of the two-way slab is affected by placing a column in the center. As a general conclusion, a significant change in the upward deflection resulted due to these parameters in linear and nonlinear static and dynamic analyses.

\section{References}

318-19 Building Code Requirements for Structural Concrete and Commentary. (2019). 318-19 Building Code Requirements for Structural Concrete and Commentary. In 318-19 Building Code Requirements for Structural Concrete and Commentary. https://doi.org/10.14359/51716937

Bondy, K. B., Bondy, K. B., \& Bondy, K. B. (2013). two-way post-tensioned slabs By By By Two-Way Post-Tensioned Slabs with Bonded Tendons. December 2012.

Colajanni, P., Recupero, A., \& Spinella, N. (2014). Design procedure for prestressed concrete beams. Computers \& Concrete, 13(2), 1-16.

Collins, M. P., \& Mitchell, D. (1991). Prestressed concrete structures (Vol. 9). Prentice Hall Englewood Cliffs, NJ.

Cooke, N., Park, R., \& Yong, P. (1981). Flexural Strength of Prestressed Concrete Members With Unbonded Tendons. Journal - Prestressed Concrete Institute, 26(6), 52-80. https://doi.org/10.15554/pcij.11011981.52.81

Du, G., \& Tao, X. (1985). Study of the Ultimate Stress of Unbonded Tendons in Partially Prestressed Concrete Beams. Jianzhu Jiegou Xuebao/Journal of Building Structures, 6(6), 2-13.

Hamed, E., \& Frostig, Y. (2006). Natural frequencies of bonded and unbonded prestressed beams--prestress force effects. Journal of Sound and Vibration, $295(1-2), 28-39$.

Kang, T. H. K., Huang, Y., Shin, M., Lee, J. D., \& Cho, A. S. (2015). Experimental and numerical assessment of bonded and unbonded post-tensioned concrete members. ACI Structural Journal, 112(6), 735-748. https://doi.org/10.14359/51688194

Khan, A. A., Pathak, K. K., \& Dindorkar, N. (2013). Cable layout design of two way prestressed concrete slabs using FEM. Computers and Concrete, 11(1), 75-91. https://doi.org/10.12989/cac.2013.11.1.075

Kumar, C. J. D., \& Venkat, L. (2013). Genetic algorithm based optimum design of prestressed concrete beam. International Journal of Civil and Structural Engineering, 3(3), 644.

Lorenc, W., \& Kubica, E. (2006). Behavior of composite beams prestressed with external tendons: Experimental study. Journal of Constructional Steel Research, 62(12), 1353-1366.

Manisekar, R., \& Senthil, R. (2006). Stress at ultimate in unbonded post tensioning tendons for simply supported beams: A state-of-the-art review. Advances in Structural Engineering, 9(3), 321-335. https://doi.org/10.1260/136943306777641922

McCormac, J. C., \& Brown, R. H. (2015). Design of reinforced concrete. John Wiley \& Sons.

Meng, G., Zhang, L. H., \& Jia, J. Q. (2013). Numerical analysis on flexural capacity of prestressed steel reinforced ultra-high strength concrete beams. Key Engineering Materials, 531, 429-434.

Naaman, A. E., \& Alkhairi, F. M. (1991). Stress at ultimate in unbonded post-tensioning tendons. Part 2. Proposed methodology. ACI Structural Journal, 88(6), 683-692. https://doi.org/10.14359/1288

Naaman, A. E., \& Alkhairi, F. M. (1992). Stress at ultimate in unbonded post-tensioning tendons: Part 2--proposed methodology. Structural Journal, 88(6), $683-692$.

Padmarajaiah, S. K., \& Ramaswamy, A. (2002). A finite element assessment of flexural strength of prestressed concrete beams with fiber reinforcement. Cement and Concrete Composites, 24(2), 229-241.

TIMOSHENKO, S., YOUNG, D. H., \& WEAVER Jr, W. (1974). Vibration Problems in Engineering.

Warnitchai, P., Pongpornsup, S., Prawatwong, U., \& Pimanmas, A. (2004). Seismic Performance of Post-. Warnitchai. 
Yang, K.-H., \& Kang, T. H.-K. (2011). Equivalent Strain Distribution Factor for Unbonded Tendon Stress at Ultimate. ACI Structural Journal, 108(2).

Yi, W., \& Du Gongchen, L. Y. (1991). Ultimate Stress in Unbonded Tendons of Partially Prestressed Concrete Beams Under Mid-Span Loading [J]. Journal of Building Structures, 6 .

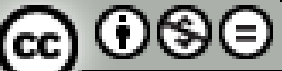

BY No ND Copyright (c) 2021. Zaki, R. and Risan, H. This work is licensed under a Creative Commons Attribution-Noncommercial-No Derivatives 4.0 International License. 